\title{
Care for children's mental health during the COVID-19 pandemic in Japan
}

\author{
Masahide Usami 1,23,*, Shoko Sasaki', Hikaru Sunakawa', Yusuke Toguchi', Syuichi Tanese', Kiyoshi Saito', \\ Rena Shinohara', Toshinari Kurokochi ${ }^{1}$, Kaori Sugimoto ${ }^{1}$, Kotoe Itagaki ${ }^{3}$, Yukino Yoshida ${ }^{2}$, Saori Namekata', \\ Momoka Takahashi ${ }^{2}$ Ikuhiro Harada ${ }^{4}$, Yuki Hakoshima' ${ }^{1}$ Kumi Inazaki ${ }^{1}$, Yuta Yoshimura', Yuki Mizumoto' \\ ${ }^{1}$ Department of Child and Adolescent Psychiatry, Kohnodai Hospital, National Center for Global Health and Medicine, Chiba, Japan; \\ ${ }^{2}$ Clinical Center of Children's Mental Health, Kohnodai Hospital, National Center for Global Health and Medicine, Chiba, Japan; \\ ${ }^{3}$ Department of Clinical Psychology, Kohnodai Hospital, National Center for Global Health and Medicine, Chiba, Japan; \\ ${ }^{4}$ Department of Social Worker, Kohnodai Hospital, National Center for Global Health and Medicine, Chiba, Japan.
}

\begin{abstract}
COVID-19 causes very serious issues all over the world. In Japan, the number of new infections in Tokyo exceeded 2,000 for the first time on 7 January 2021, and the situation is becoming increasingly serious. Japan is in the midst of its third big outbreak. Japanese society will face several challenges regarding children's mental health during the COVID-19 pandemic. In order to develop healthy minds in children, it is important to view the changes in children's minds in a positive light and promote their healthy emotional development while correctly fearing COVID-19. This sense of social stagnation and uncertainty is likely to increase feelings of insecurity and isolation among children. It is also important to prevent the repetition of child abuse in the home due to parental unemployment, alcohol problems, and reduced contact with non-family members in stay home and the recession as a result of COVID-19. During the pandemic, adults should be sensitive to the unusual behavior of children. We propose six suggestions of care for children during the COVID-19 pandemic.
\end{abstract}

Keywords: child, mental health, COVID-19, pandemic, school closure

COVID-19 causes very serious issues all over the world. In Japan, the number of new infections in Tokyo exceeded 2,000 for the first time on 7 January 2021, and the situation is becoming increasingly serious. Japan is in the midst of its third big outbreak. In many countries, children's mental health during the COVID-19 pandemic is a growing problem $(1,2)$. COVID-19 has caused unprecedented challenges at all levels of society. Therefore, Japanese society will face several challenges regarding children's mental health during the COVID-19 pandemic.

Children's daily activity during COVID-19 pandemic in Japan. There were significant changes in children's mental health during the first outbreak. Children's daily life was changed after Japanese Prime Minister ordered all elementary and junior high schools in Japan to close their schools temporarily from 2 March 2020 to spring break in response to the explosive spread of the disease in Japan. After schools were reopened in June, the school day was dispersed. It seemed as if the spread of the infection was under control, but then COVID-19 once again raged, and the number of infections across the country began to increase. In the summer, the classroom windows are open while class is in session.
If there is a cluster outbreak in a school, the school is closed for a few days of disinfection. School travels and sports events had been cancelled, and the regular school curriculum has not been implemented.

Children's mental health during COVID-19 pandemic in Japan. Every child lives and grows up in a group at home and at school. The need for peer groups is especially high during adolescence. Adolescents grow up independent and prioritize peer connections over their parents, which can pose significant challenges to young people's healthy emotional development if it is stifled. Adolescents may grieve the rites of passage they were supposed to experience and may feel anxious about an uncertain future in the face of COVID-19. With the spread of COVID-19, many children have had a difficult time participating in population activities. In order to develop healthy minds in children, it is important to view the changes in children's minds in a positive light and promote their healthy emotional development while correctly fearing COVID-19. This sense of social stagnation and uncertainty is likely to increase feelings of insecurity and isolation among children. It is also important to prevent the repetition of child abuse in the home due to parental unemployment, 
alcohol problems, and reduced contact with non-family members in stay home and the recession as a result of COVID-19 (Figure 1).

COVID-19 pandemic effects not only directly affect the child, but also greatly affect the environment surrounding the child, which ultimately affects the child; measures being taken to control the spread of COVID-19 put the child at a higher risk of neglect and abuse, and put the child at a higher risk for neglect and abuse than COVID-19 as a "second wave" (3). Furthermore, some children and adults were enthusiastic about game devices and they could not buy game devices before COVID-19 pandemic (4-6). Stay home caused these problems.

Child and adolescent psychiatry during COVID-19 pandemic in Japan. During COVID-19 pandemic, there are unprecedented symptoms from childhood to adulthood (1). Some children have noted some psychiatric symptoms during pandemic and will often lead to early visits to child psychiatrists and pediatricians $(1,7)$. Figure 2 shows the number of outpatients who visited the Department of Child and Adolescent Psychiatry, Kohnodai Hospital, National Center for Global Health and Medicine in 2020 compare with 2019. The number of outpatients in follow-up examinations is decreasing. However, the number of outpatients in the first visit increased after 1 April . Especially, the number of children with anorexia nervosa has had a large increase of 2.2 times from 2019 to 2020 in our hospital, which is the same as other counties (8). In a questionnaire to the parents of outpatients, 63 (44\%) of 143 responses postponed their visit to the hospital (7). The reasons for this postponement were infection control not only for the children and their parents but also for the grandparents living with them, not having child issues, but still having medicine left.

Care for children's Mental health during COVID-19

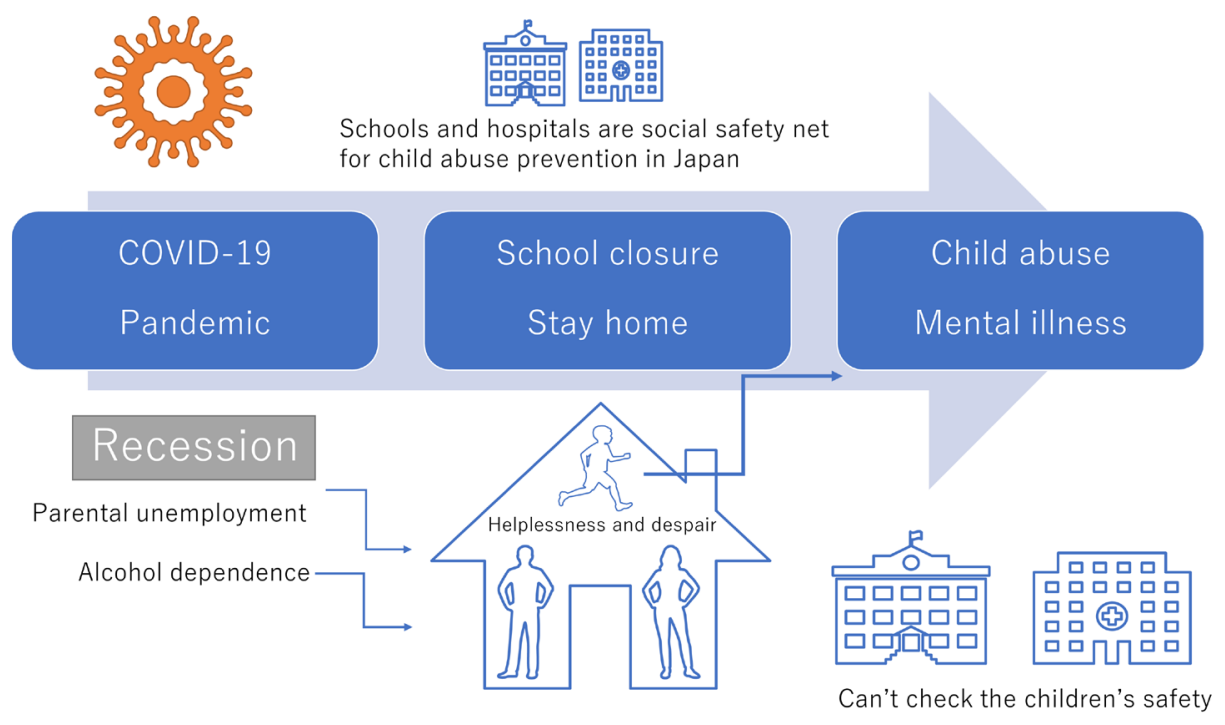

Figure 1. Child abuse under COVID-19 pandemic. Measures being taken to control the spread of COVID-19 put the child at a higher risk of neglect and abuse.

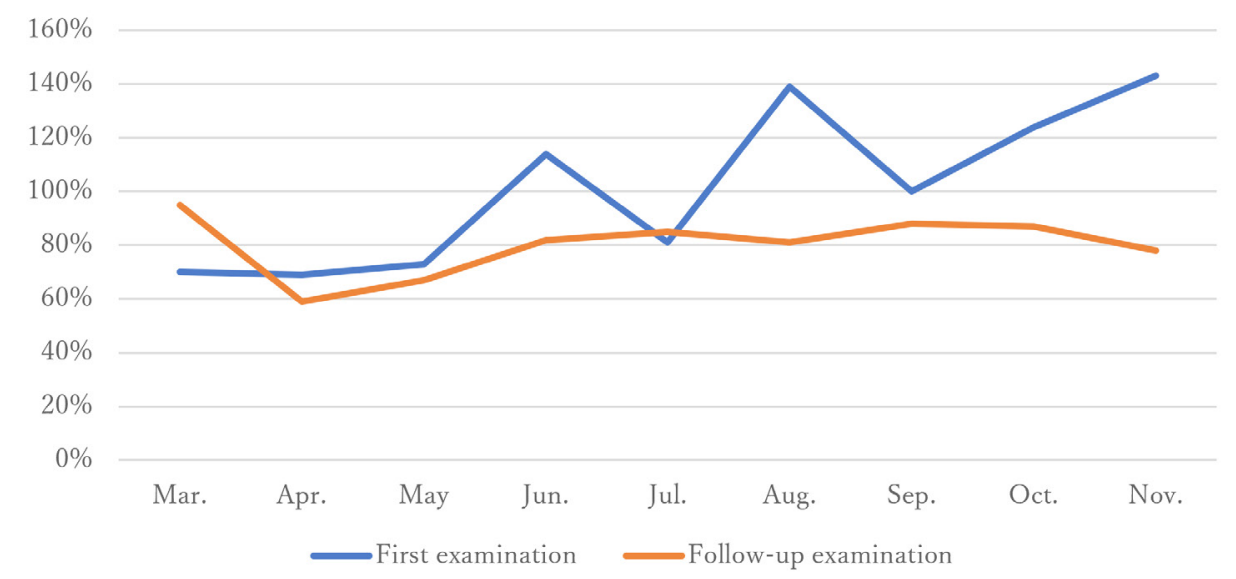

Figure 2. The number of outpatients of first and follow-up examination in 2020 compared with 2019. 


\section{Table 1. Six suggestions of care for children during COVID-19 pandemic}

\begin{tabular}{|c|c|}
\hline No. & Suggestions \\
\hline 1 & Some children and parents misunderstood knowledge about COVID-19. The correct information can help reduce undue anxiety. \\
\hline 2 & $\begin{array}{l}\text { It is a natural reaction to children's anxiety in pandemic. In addition children usually are not able to be aware of this change on their } \\
\text { own. Children are characterized by a tendency for changes in feelings to lead to physical symptoms. }\end{array}$ \\
\hline 3 & $\begin{array}{l}\text { Discuss changes in the child's mood and behavior, changes in appetite, sleep and other aspects of life. Clinicians should talk about } \\
\text { the changes and concerns without rushing to resolve them. }\end{array}$ \\
\hline 4 & Look for children's positive changes and positive changes as a family. \\
\hline 5 & $\begin{array}{l}\text { Solution for problem of Internet gaming need strong relationships between parents and children to discuss and work together to } \\
\text { address problems. The discussion about the problem causes rebellion and resistance from the child. It is normal for there to be a gap } \\
\text { between the attitudes of the child and family to solve. The relationship between parent and child on a daily basis is important. }\end{array}$ \\
\hline 6 & $\begin{array}{l}\text { Key points of communication with the child: } \\
\text { i) Do not blame the child. } \\
\text { ii) Discuss the rules with respect to the child's will and opinion. } \\
\text { iii) Praise the child. }\end{array}$ \\
\hline
\end{tabular}

pandemic in Japan. During pandemic, adults should be sensitive to the unusual behavior of children. Children who are less likely to be infected and less likely to become seriously ill are protecting their stay homes, washing their hands and wearing masks to protect adults who are more likely to have severe illness. Children who are less likely to be infected and less likely to have a serious state, masks to protect adults who are more likely to have a severe state. Adults should remember to appreciate their children.

In conclusion, the first step is to take an interest in your child about how they understand COVID-19. With so much information coming from the internet and social networking sites, it is not uncommon for children to be misinformed and overly anxious. It is important to discuss COVID-19 with children, whether you are a parent, teacher or physician. As summarized in Table 1, we propose six suggestions of care for children during COVID-19 pandemic.

\section{Funding: None.}

Conflict of Interest: The authors have no conflicts of interest to disclose.

\section{References}

1. Stavridou A, Stergiopoulou AA, Panagouli E, Mesiris G, Thirios A, Mougiakos T, Troupis T, Psaltopoulou T, Tsolia M, Sergentanis TN, Tsitsika A. Psychosocial consequences of COVID-19 in children, adolescents and young adults: A systematic review. Psychiatry Clin Neurosci. 2020; 74:615-616.

2. Ellis WE, Dumas TM, Forbes LM. Physically isolated but socially connected: Psychological adjustment and stress among adolescents during the initial COVID-19 crisis. Can J Behav Sci. 2020; 52:177-187.

3. Institute of Health Visiting. Is a secondary pandemic on its way? Published 6th April 2020. https://ihv.org.uk/ news-and-views/voices/is-a-secondary-pandemic-on-itsway/ (accessed July 31, 2020).

4. Paulus FW, Ohmann S, von Gontard A, Popow C. Internet gaming disorder in children and adolescents: a systematic review. Dev Med Child Neurol. 2018; 60:645-659.

5. Sussman CJ, Harper JM, Stahl JL, Weigle P. Internet and video game addictions: diagnosis, epidemiology, and neurobiology. Child Adolesc Psychiatr Clin N Am. 2018; 27:307-326.

6. Han DH, Yoo M, Renshaw PF, Petry NM. A cohort study of patients seeking Internet gaming disorder treatment. J Behav Addict. 2018; 7:930-938.

7. Usami M. A child psychiatrist's perspective on children's mental health (Vol. 13) child and adolescent psychiatry during COVID-19 pandemic. Pharm Mon. 2021; 63(2). (In Japansese)

8. Castellini G, Cassioli E, Rossi E, Innocenti M, Gironi V, Sanfilippo G, Felciai F, Monteleone AM, Ricca V. The impact of COVID-19 epidemic on eating disorders: A longitudinal observation of pre versus post psychopathological features in a sample of patients with eating disorders and a group of healthy controls. Int J Eat Disord. 2020; 53:1855-1862.

Received September 9, 2020; Revised February 12, 2021; Accepted February 22, 2021.

Released online in J-STAGE as advance publication March 6, 2021.

*Address correspondence to:

Masahide Usami, Department of Child and Adolescent Psychiatry, National Center for Global Health and Medicine, Kohnodai Hospital, 1-7-1 Kohnodai, Ichikawa, Chiba 2728516, Japan.

E-mail: usami.masahide@hospk.ncgm.go.jp 